\title{
Decision-Making Framework for Implementing Safer Human-Robot Collaboration Workstations: System Dynamics Modeling
}

\author{
Guilherme Deola Borges ${ }^{1, *} \mathbb{D}^{\infty}$, Angélica Muffato Reis ${ }^{1}$, Rafael Ariente Neto ${ }^{2}{ }^{\circ}$, Diego Luiz de Mattos ${ }^{1}$, \\ André Cardoso ${ }^{1}$, Hatice Gonçalves ${ }^{1}$, Eugenio Merino ${ }^{2}$, Ana Colim ${ }^{1}\left(\mathbb{D}\right.$, Paula Carneiro ${ }^{1}\left(\mathbb{D}\right.$ and Pedro Arezes ${ }^{1}(\mathbb{D}$ \\ 1 ALGORITMI Research Centre, School of Engineering, University of Minho, 4800-058 Guimarães, Portugal; \\ angelicamufato@gmail.com (A.M.R.); diegoclerigo@yahoo.com.br (D.L.d.M.); \\ andrecardoso92@gmail.com (A.C.); hatice.kirkici@gmail.com (H.G.); ana.colim@dps.uminho.pt (A.C.); \\ pcarneiro@dps.uminho.pt (P.C.); parezes@dps.uminho.pt (P.A.) \\ 2 Design Management Center (NGD), Design and Usability Laboratory (LDU), Production Engineering \\ Department, Federal University of Santa Catarina, Florianópolis 88040-535, Brazil; \\ rafael.ariente@gmail.com (R.A.N.); eugenio.merino@ufsc.br (E.M.) \\ * Correspondence: guilhermedeola@gmail.com; Tel.: +351-961-944-842
}

\section{check for}

updates

Citation: Borges, G.D.; Reis, A.M.; Ariente Neto, R.; Mattos, D.L.d.; Cardoso, A.; Gonçalves, H.; Merino, E.; Colim, A.; Carneiro, P.; Arezes, P. Decision-Making Framework for Implementing Safer Human-Robot Collaboration Workstations: System Dynamics Modeling. Safety 2021, 7, 75. https://doi.org/10.3390/ safety7040075

Academic Editor: Tom Brijs

Received: 12 August 2021

Accepted: 25 October 2021

Published: 27 October 2021

Publisher's Note: MDPI stays neutral with regard to jurisdictional claims in published maps and institutional affiliations.

Copyright: (c) 2021 by the authors. Licensee MDPI, Basel, Switzerland. This article is an open access article distributed under the terms and conditions of the Creative Commons Attribution (CC BY) license (https:/ / creativecommons.org/licenses/by/ $4.0 /)$.
Abstract: Human-Robot Collaboration (HRC) systems are often implemented seeking for reducing risk of Work-related Musculoskeletal Disorders (WMSD) development and increasing productivity. The challenge is to successfully implement an industrial HRC to manage those factors, considering that non-linear behaviors of complex systems can produce counterintuitive effects. Therefore, the aim of this study was to design a decision-making framework considering the key ergonomic methods and using a computational model for simulations. It considered the main systemic influences when implementing a collaborative robot (cobot) into a production system and simulated scenarios of productivity and WMSD risk. In order to verify whether the computational model for simulating scenarios would be useful in the framework, a case study in a manual assembly workstation was conducted. The results show that both cycle time and WMSD risk depend on the Level of Collaboration (LoC). The proposed framework helps deciding which cobot to implement in a context of industrial assembly process. System dynamics were used to understand the actual behavior of all factors and to predict scenarios. Finally, the framework presented a clear roadmap for the future development of an industrial HRC system, drastically reducing risk management in decision-making.

Keywords: human-robot collaboration; system dynamics; human factors; ergonomics; framework

\section{Introduction}

The recent advance in industrial technology is dealing with complex problems: to increase productivity without neglecting human factors; to look for specific improvements in spite of considering the whole system dynamics; and to solve today's problems without creating a new one to be addressed in the future [1,2]. The implementation of a HumanRobot Collaboration (HRC) system is often aimed at reducing Work-related Musculoskeletal Disorders (WMSD) at the same time that increases production, by combining the skills of both humans and robots $[3,4]$.

Workers are exposed daily to physical and mental workplace hazards [5], especially in assembly workstations in industry [6]. Ergonomic risks lead to absenteeism due to WMSD $[7,8]$. In order to mitigate those issues, a possible ergonomic intervention is to implement an industrial HRC system, which combines both robot and human skills. Moreover, a cobot performs the task like a co-worker, with no physical barriers to help achieve a goal [9]. As a co-worker, it is also expected to increase productivity [10].

The implementation of an industrial HRC system is not simple and there are many organizational factors to consider [11,12]. Moreover, there are critical technical issues, 
ergonomic, safety, and economic aspects to consider when evaluating scenarios with a cobot $[13,14]$. By doing a correct assessment of the current workstation it is possible to run a simulation model [15], which brings more data for understanding the system and ultimately for a correct decision.

Therefore, the aim of this study was to develop a decision-making framework for implementing HRC systems. The contribution highlights of this work follow: a framework to decide which collaborative robotic system to choose; a system dynamic model that considers Level of Collaboration (LoC), physical, and mental workloads with simulation of scenarios for absenteeism and productivity; and a case study applying a roadmap to reduce risk management in decision-making. The system dynamics model is limited to the boundaries chosen, which excludes other variables that might be useful depending on the characteristics screened for a specific workplace. The article is structured as follows:

- An introduction to the fundamental concepts related to the problem being addressed, namely: HRC, ergonomics, and system dynamics.

- A decision-making framework proposal, starting with the problem definition, followed by an assessment of the current workstation, a computational modeling of the system, the evaluation of possible solutions, and the final decision regarding an industrial HRC system.

- A case study applying the aforementioned framework in a manual assembly workstation that intends to implement an industrial HRC.

\section{Fundamental Concepts}

\subsection{Human-Robot Collaboration}

The fourth industrial revolution is characterized by smart and autonomous systems [9]. Cobots allow workstations without barriers and their implementation is a potential solution when planning to improve workstation conditions. This solution combines typical robot's capabilities (accuracy, speed, and repeatability) with human skills (adaptability, dexterity, and perception) aimed at achieving a common goal [16]. According to [17], there are five LoC with increasing complexity, competences, and cost: Level 0 (cell), Level 1 (coexistence), Level 2 (synchrony), Level 3 (cooperation), and Level 4 (collaboration). The design of HRC workstations has to integrate some requirements in order to propose task allocations [18,19]: (Human) posture, strength, biomechanics and cognition; (Robot) joints position, velocity, acceleration and sensors; (Human and Robot interaction) force or feedback force; and (Process) manufacturing goals, such as cycle time and quality. Moreover, when designing an HRC system and considering ergonomic aspects, it is expected to reduce human workload, WMSD risk factors, and production costs. Therefore, many of the current workstations should consider the implementation of a cobot to work in a safe, ergonomic, and efficient way. Accordingly, a successful implementation of a HRC system depends on considering ergonomics [11].

\subsection{The Role of Ergonomics in the Workstation Transformations}

Ergonomics is the discipline that studies the relationship between man and work, seeking for adaptation of the workstation environment for the worker to carry out his activities [20]. New technologies and interventions in industry increases environment complexity, which means that ergonomics should be treated using a systematic view [21]. Organizations often do not get the most ergonomic benefits when they introduce new technologies [11]. It is confirmed by [22] that optimizing simultaneously task allocation while taking into account ergonomic aspects improves the efficiency and acceptance. Moreover, the concept design considers human mental and physical viewpoints at the same time by proposing a hand-guiding on the robot for the users to have control over the system, having the robot as a helper instead of a robot giving an object. A systemic view that predicts scenarios regarding ergonomics and productivity is needed, and not considering ergonomics in HRC systems may present undesired effects [23]. 


\subsection{System Dynamics}

System dynamics is a method to navigate the complex systems. It is grounded in the theory of nonlinear dynamics and feedback control developed in mathematics, physics, and engineering to understand a system's behavior [24]. Through this method, it is possible to design, to model, to simulate, to understand, and finally to make good decisions in complex systems taking both short- and long-term behavior into consideration. These systems exist in an environment within boundaries and are characterized by their structure, elements that interact, processes, goals, inputs, and outputs. As seen in [15], computer simulations are controlled experimental environments in which different possibilities can be tested without investing a great amount of resources before evaluating and deciding.

The interest in this topic has grown recently as stated in [25] that ergonomic study should always involve a systemic view, with any analysis or interventions considering the context as a whole. It was found in [26] that using system dynamics has potential to increase safety in complex systems that cannot be achieved with traditional approaches [27]. Similarly, ergonomics is also of crucial importance in the implementation of an industrial HRC. The three ergonomic dimensions have been considered in [28] when designing workstations for manual production and maintenance processes. In [29], employees suffering from injuries result in worse productivity and quality of products, which leads to losses and indirect costs. Indirect costs like absenteeism are often difficult to measure and are excluded from production costing models. A literature review found ergonomic frameworks with the following characteristics: focusing on the physical assessment [30]; an integrated framework addressing both physical and psychological levels [31]; an agent-based model included ergonomics in terms of assessing risk levels, considering how pain and fatigue affect performance [32]; an optimized hierarchical model to improve production time and ergonomics for decision-making [33]; and insights on the productivity and its ergonomic impact on workers [34]. It demonstrates that a framework is needed in order to avoid injury, poor quality, low production, and to decrease costs in complex systems.

\section{Decision-Making Framework}

A logical decision-making process was built analyzing the current situation, evaluating the available possibilities, and finally deciding what to do based on information about the system. This methodology was chosen to create a complete roadmap framework to be used together with system dynamics. It was divided in the following phases: (i) assessment of the current workstation by applying methods from the three ergonomic dimensions (physical, cognitive, and organizational) and collecting production data; (ii) computational modeling of the key factors of the system considering different LoC; (iii) simulation and prospection of scenarios regarding absenteeism and productivity when inserting a cobot into a production system; and (iv) technical, ergonomic, safety, and economic evaluation for a better decision-making.

\subsection{Problem Definition}

In the cases where this framework can be useful, usually the problem is related to both absenteeism due to WMSD and productivity. The reason is simple: by introducing an industrial HRC system, it is expected to reduce the human efforts regarding postures and repetitiveness. Additionally, by including automation into the production line, it is expected to increase productivity. Therefore, the framework is designed for those who need to choose what kind of cobot to install or what LoC fits better in the long term of this cooperation.

\subsection{Ergonomic Assessment}

Based on the characteristics of an HRC workstation, ergonomic methods from the three ergonomic domains have been used to assess the risks. The framework provides guidance, but does not suggest a strict set of tools, allowing more adaptability for the practitioner who must navigate within a particular context. Four physical risk levels and two mental 
risk levels were defined by the simulation modelers in order to weight the overall human workload. It is suggested to use at least one from each of the following domains:

\subsubsection{Organizational}

Ergonomic methods to assess organizational factors are mandatory to allow building the causal loop diagram (CLD) [15], a diagram that represents the actual system under study. There are two main options to choose for a complete workstation description, according to preferences:

- Ergonomic Analysis of Work [35] —an observational screening method to assess the workstation. It is divided into five stages: demand analysis, task analysis, activity analysis, diagnosis, and recommendations. By applying this method, it is possible to identify the main variables of a system and their interconnections in order to build the CLD of a dynamic system.

- Ergonomic Workplace Analysis (EWA)/Finnish Institute of Occupational Health (FIOH) [36,37] - a time-based checklist observational method to assess the main risk factors of the workstation. It is divided into 14 topics: workspace; general physical activity; lifting tasks; work postures and movements; risk of accident; work content; restrictiveness; workers' communication; decision-making; work repetitiveness; level of required attention; lighting; thermal conditions; and noise.

\subsubsection{Physical}

The physical workload is directly related to high force loads, awkward postures, and repetitive movements, which lead to WMSD and absenteeism [38]. To understand the system, this framework suggests choosing at least one of the ergonomic methods in this domain to assess the risks related to the workstation. The method should be chosen according to preferences and the specific characteristics of an assembly task:

- $\quad$ Rapid Upper Limb Assessment (RULA) [39]—an observational ergonomic tool that considers biomechanical and postural load requirements of job tasks. It is a good and widely used method to assess physical workload, except for not considering the duration of exposures.

- Ergonomic Assessment Worksheet (EAWS) [40]—a screening tool developed from the automotive industry. The method combines aspects of manual load handling and assesses the risks of body postures, action forces, manual handling, and upper members.

- National Institute for Occupational Safety and Health (NIOSH equation) [41]-a method to assess the risk of low-back disorders in jobs with lifting tasks. It is based on biomechanical, physiological, psycho-physiological, and epidemiological data. It is a well-documented method.

- Key Indicator Method for Manual Handling Operations (KIM-MHO) [42]—an observational method often used for assembly tasks. It aims to evaluate the probability of physical overload and possible consequences of WMSD.

- Revised Occupational Repetitive Actions checklist (OCRA) [43] —a method to screen the risk associated with upper-limbs in repetitive tasks. This method takes into account the recovery periods.

- Nordic Musculoskeletal Questionnaire (NMQ) [44]—a standardized questionnaire used to evaluate and to characterize musculoskeletal symptomatology perceived by workers, considering nine body regions. Perceived pain intensity is assessed using a numerical scale for each of the body regions.

- Electromyography (EMG) $[45,46]$-a direct risk measurement technique to deal with physiological parameters of the human body when performing dynamic tasks. It allows identifying the muscle fatigue index, which is the cause of WMSD, by capturing the bioelectric signal emitted during muscle contractions.

Each one of the physical workload methods are based on their own scale to assess the physical risk of a task. These scales are usually named as acceptable risk, low risk, 
medium risk, and high risk. As this framework intends to use the risk level in a simulation model, the different output values from the selected physical methods were converted into a numerical scale of four physical risk levels. According to the aforementioned references, Table 1 presents the four suggested physical risk levels that can be obtained for each ergonomic method chosen.

Table 1. Physical risk levels based on the output scores of each ergonomic method.

\begin{tabular}{ccccccccc}
\hline $\begin{array}{c}\text { Physical } \\
\text { Risk Level }\end{array}$ & Meaning & $\begin{array}{c}\text { RULA } \\
\text { Scores }\end{array}$ & $\begin{array}{c}\text { EAWS } \\
\text { Points }\end{array}$ & $\begin{array}{c}\text { NIOSH } \\
\text { Lifting Index }\end{array}$ & $\begin{array}{c}\text { KIM-MHO } \\
\text { Points }\end{array}$ & $\begin{array}{c}\text { OCRA } \\
\text { Checklist }\end{array}$ & $\begin{array}{c}\text { NMQ Borg } \\
\text { Scale }\end{array}$ & $\begin{array}{c}\text { EMG } \\
\% \text { MVC }\end{array}$ \\
\hline I & Acceptable risk & 1 or 2 & 0 to 25 & $<1$ & $<20$ & $<7.5$ & 0 & 0 to $<1$ \\
II & Low risk & 3 or 4 & 26 to 50 & 1 to $<2$ & 20 to $<50$ & 7.6 to 11.0 & 1 to 3 & 1 to $<10$ \\
III & Medium risk & 5 or 6 & & 2 to $\leq 3$ & 50 to $<100$ & 11.1 to 22.5 & 4 to 6 & 10 to $\leq 14$ \\
IV & High risk & 7 & $>50$ & $>3$ & $\geq 100$ & $\geq 22.6$ & 7 to 10 & $>14$ \\
\hline
\end{tabular}

\subsubsection{Cognitive}

Mental workload is often ignored when assessing the risks related with a workstation. However, many authors emphasize the importance in considering this factor in a system $[5,47,48]$, especially in the long term. There are three main methods to choose in this domain:

- $\quad$ NASA Task Load Index (NASA-TLX) [49]—a widely applied questionnaire used to assess mental workload, including work systems with a high level of complexity. It evaluates mental demand, physical demand, temporal demand, effort, frustration, and performance. A numerical scale is used to assess the workload perceived by the worker for each of the six items.

- $\quad$ Subjective Workload Assessment Technique (SWAT) [50]—it was originally designed to assess aircraft cockpit workload. It is divided in two phases: scale development and scale scoring. The three dimensions measured are: time, mental effort, and psychological stress.

- Electrodermal Activity (EDA) [51]—a technique to identify changes in the skin's electricity by wearable sensors. It may be employed for assessing emotional states and to understand the worker's mental status. EDA is divided in electrodermal response (EDR) that reflects short-term stress, and electrodermal level (EDL) is more related to risk perception and a relevant indicator of long-term stress.

Similarly, to the physical workload, as input to the simulation model, the different output values from the selected mental methods were converted into a numerical scale. According to the aforementioned references, Table 2 presents the two suggested mental risk levels that can be obtained for each method chosen.

Table 2. Mental risk levels based on the output scores of each method.

\begin{tabular}{ccccc}
\hline $\begin{array}{c}\text { Mental Risk } \\
\text { Level }\end{array}$ & Meaning & $\begin{array}{c}\text { NASA-TLX } \\
\text { Overall Workload }\end{array}$ & SWAT Value & $\begin{array}{c}\text { EDA } \\
\text { EDR's Mean Value }\end{array}$ \\
\hline I & Low risk & 0 to $<60$ & 0 to $<60$ & Below 0.5 \\
II & High risk & 60 to $<100$ & 60 to $<100$ & Above 0.5 \\
\hline
\end{tabular}

\subsection{Production data}

The current data of the production line are necessary to model the dynamics of a system. In this regard, based on the literature $[15,24]$, the most important factors suggested by this framework are:

- Production goals: number of pieces to be assembled in a period of time.

- Takt time: assembly duration time needed to match the production goals.

- Cycle time: the time it takes to complete one assembly.

- Absenteeism due to WMSD: the sick leave rate due to musculoskeletal issues. 
- Number of workers: the sum of workers in the production line.

It means that a correct assessment on production is sufficient with the above factors. However, for understanding the dynamics of an actual system other factors may be useful as well (e.g., gender, age, seniority, previous injuries, or illnesses).

\subsection{System Dynamics}

This framework suggests to model the system under study using both ergonomic and production data. Modeling is divided into conceptual definition, structural description, and simulation. It aims at representing the most important factors and their interconnections with a focus on solving a problem. In this case, the context also includes the insertion of a cobot considering different LoC into the system to evaluate scenarios. As a result, it is expected to maximize worker's well-being and system performance. An example of conceptual description, the CLD with the above-mentioned factors is represented in Figure 1. In the conceptual definition, four information feedback cycles are relevant: "production self-regulation", "learning by repetition", "limitation due to disease incidence", and "reinforcement of mental workload".

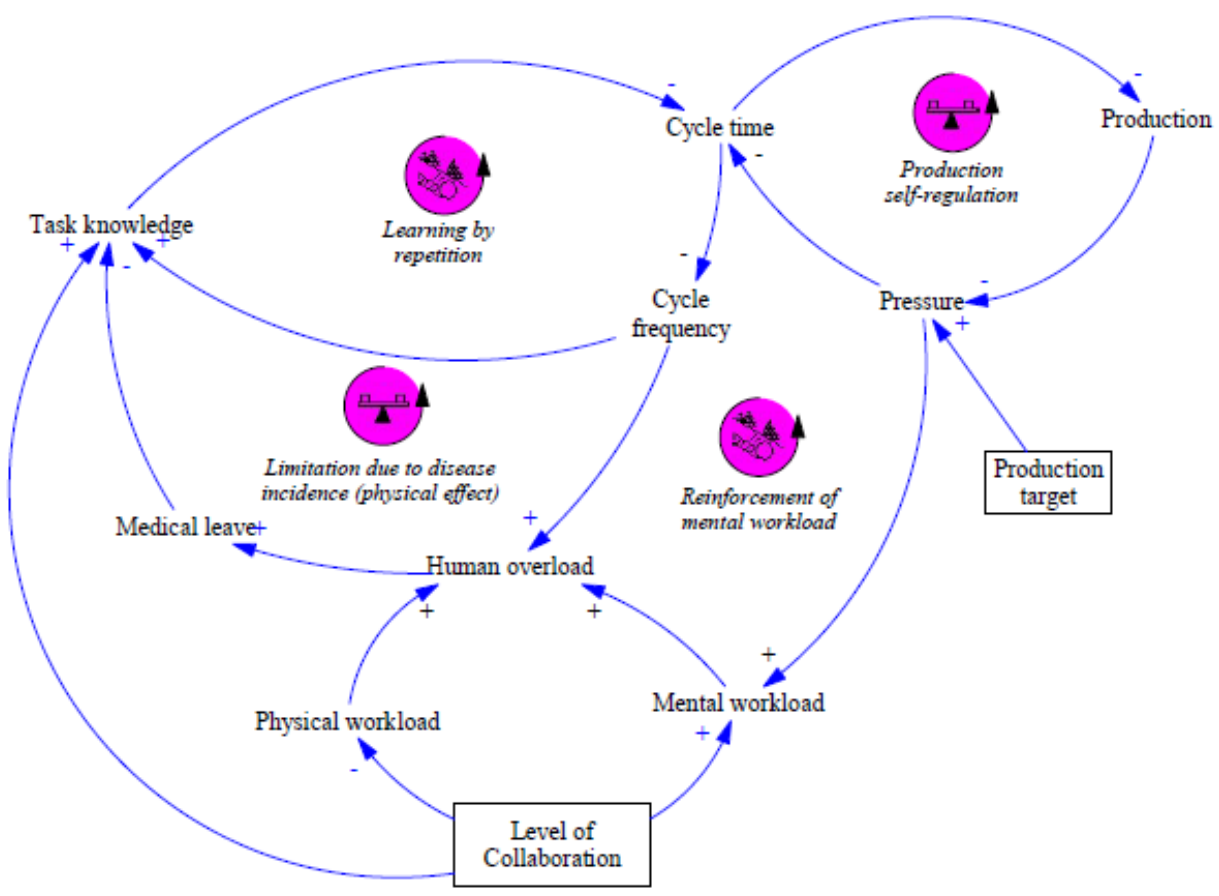

Figure 1. Causal Loop Diagram for an industrial HRC system.

As the problem is related to productivity and absenteeism due to WMSD, the hypothesis to be considered is at what extent the robot will collaborate. It is widely demonstrated that the intervention of an industrial HRC system increases productivity and decreases ergonomic efforts [52-54]. Moreover, there are different competence levels for a cobot [55] to be chosen, which are very much related to the LoC. Which LoC is best for the current situation is what a simulation model can answer.

Therefore, by applying a structural and mathematical model, the Stock and Flow Map (SFM) is needed to understand what was established in the conceptual diagram, maintaining the cycles and the established concept itself. There are many examples of SFM in the literature that can be adapted to the current system; however, it must be tested and calibrated according to the situation. Table 3 presents the description of competences regarding safety and ergonomics, as well as the influence of LoC on the model. 
Table 3. Description of competence levels with their influence on the model.

\begin{tabular}{|c|c|c|c|c|c|}
\hline System & 0 & 1 & 2 & 3 & 4 \\
\hline \multirow[t]{2}{*}{$\begin{array}{c}\text { Safety and human } \\
\text { support of a cobot } \\
\text { [55] }\end{array}$} & \multirow[t]{2}{*}{$\begin{array}{c}\text { Current } \\
\text { workstation } \\
\text { without cobot. }\end{array}$} & $\begin{array}{c}\text { ISO/TS 15,066 [56] } \\
\text { Safety-rated } \\
\text { monitored stop. }\end{array}$ & $\begin{array}{l}\text { ISO/TS 15,066 } \\
\text { Hand-guiding. }\end{array}$ & $\begin{array}{l}\text { ISO/TS 15,066 } \\
\text { Speed and } \\
\text { separation } \\
\text { monitoring. }\end{array}$ & $\begin{array}{l}\text { ISO/TS 15,066 } \\
\text { Power and force } \\
\text { limiting. }\end{array}$ \\
\hline & & $\begin{array}{l}\text { Cobot performs } \\
\text { repetitive, and/or } \\
\text { dangerous tasks, } \\
\text { and sounds alarm } \\
\text { in emergency. }\end{array}$ & $\begin{array}{l}\text { Cobot performs } \\
\text { ergonomically } \\
\text { challenging tasks: } \\
\text { dirty, hot, humid, } \\
\text { and noisy } \\
\text { environment. } \\
\text { Cobot issues safety } \\
\text { warnings and } \\
\text { suggests help only } \\
\text { in emergencies. }\end{array}$ & $\begin{array}{l}\text { Cobot brings tools } \\
\text { or parts next to the } \\
\text { operator and takes } \\
\text { them away. Cobot } \\
\text { issues reminders, } \\
\text { and draws } \\
\text { attention to } \\
\text { evolving } \\
\text { situations. }\end{array}$ & $\begin{array}{l}\text { Cobot holds } \\
\text { and/or } \\
\text { manipulates the } \\
\text { tool or work piece. } \\
\text { May initiate tasks: } \\
\text { 'let me hold it'. } \\
\text { May suggest help } \\
\text { in extreme cases. }\end{array}$ \\
\hline Mental & \multicolumn{5}{|c|}{ Mental workload increases with the complexity of the task $[47,52]$} \\
\hline Physical & \multirow{2}{*}{\multicolumn{5}{|c|}{$\begin{array}{l}\text { Physical workload decreases when cobot assumes the tasks related with loads and repetitiveness [57,58]. } \\
\text { Knowledge of the task can assume different values depending on the specific workstation [15]. }\end{array}$}} \\
\hline Knowledge & & & & & \\
\hline
\end{tabular}

The system dynamics simulation phase is reserved to prospect scenarios for analysis of different possibilities. It aims at understanding the system to establish risk indicators, to propose organizational changes and ergonomic interventions, which finally support management evaluation of the system performance.

\subsection{Management Evaluation and Decision}

The evaluation process by the management is critical in deciding whether to include a robot in the system. After analyzing the prospected scenarios, there are other managerial aspects to consider. The minimal phases to be considered are shown in Figure 2.
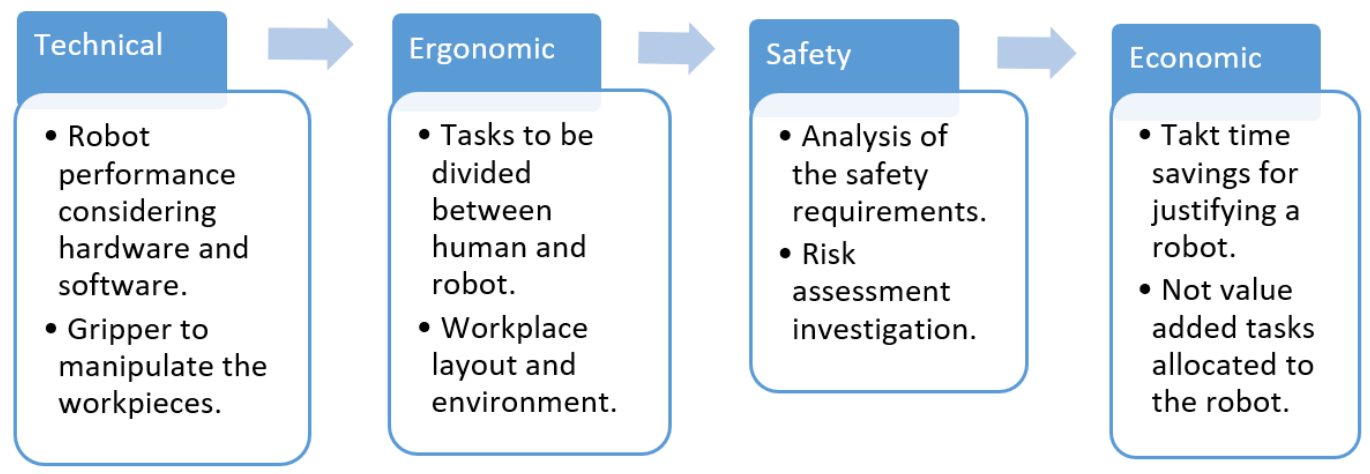

Figure 2. Managerial evaluation analysis.

The technical evaluation considers the technologies available (robot arm, gripper, sensors), the new workstation configuration (shop floor space), computational systems to be integrated (interfaces, hardware, and software limitations), and even the experience and training of workers. Technical issues might be a critical variable when implementing a cobot. Ergonomic evaluations were already discussed during the first assessment.

Especially when deciding which tasks are to be allocated to the worker, the new workstation also needs special ergonomic considerations. Postures (workstation layout), frequency of repetitive actions, workloads, and time pressure as well as safety requirements. The new productivity goals are limited by ergonomic and safety issues. Therefore, when evaluating economics, every variable is important. The economic evaluation might be estimated considering the non-value added tasks that will be automated [14], as these tasks usually consume time and production resources. Therefore, it is possible to compare 
the savings with the investment. Another way to manage the economic evaluation is formulated in [55], where the cobot savings percentage of the manual takt time should be higher than the minimal required saving to justify implementing a cobot in the system.

There are other aspects that could be considered when evaluating the inclusion of a cobot for example, the product and process quality, which can be evaluated by the level of process variability and its standardization level [14]. A managerial decision is based on the available information. In order to avoid making decisions based on half information or mental models, this framework presented a logical roadmap to bring relevant data to be considered and help deciding at this last stage of the framework:

- Summarizing the most important factors of the current situation;

- Including the system dynamic model is key to understanding the whole system;

- Considering the organizational recommendations from the simulation and prospection model;

- Relying on the technical, ergonomic, safety, and economic evaluations;

- Defining the new productivity and absenteeism goals.

The managerial team decides which cobot to implement. As the introduction of a new technology, it is important to have such a global approach. Figure 3 summarizes the proposed roadmap for a decision-making in HRC systems.

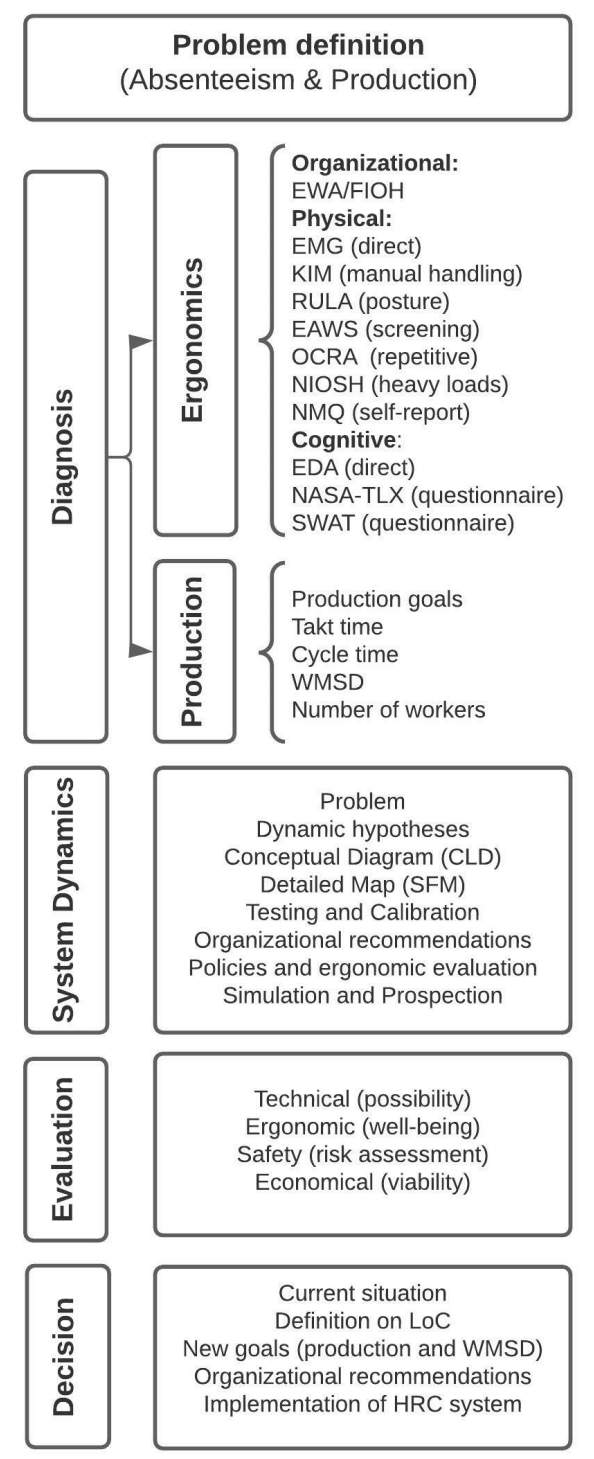

Figure 3. Phases of the developed framework. 


\section{Case Study}

A workstation for the manual assembly of electrical components in Portugal was planning to incorporate an industrial HRC system. According to the company's information, the workstation deals with recurrent absenteeism due to WMSD. Therefore, this framework was applied in order to help decision makers which system to choose. Figure 4 presents the steps towards the objectives of this case study.

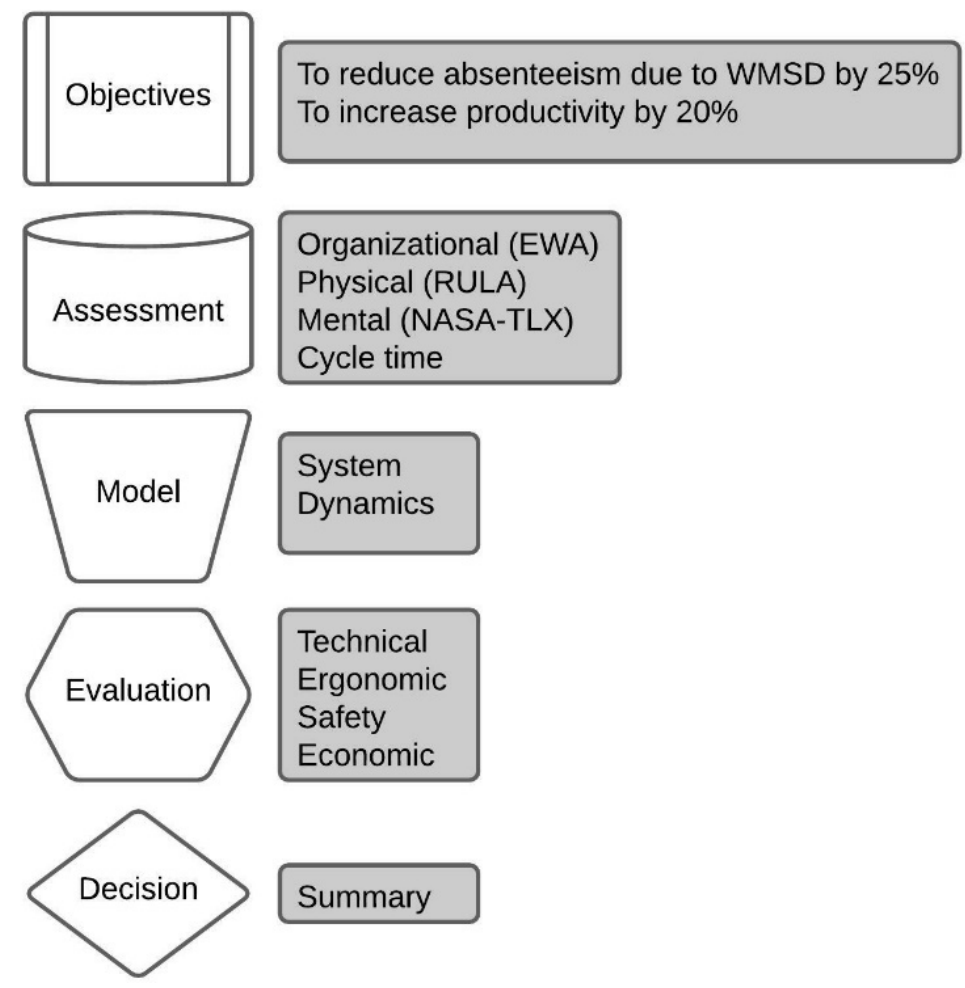

Figure 4. Applied framework for ergonomic assessment in a workstation with an HRC system.

\subsection{Objectives}

Absenteeism is often the starting point of ergonomic interventions in a production line, as it directly impacts in human being as well as productivity [59]. According to the company, the main goal is to reduce absenteeism due to WMSD by $25 \%$ and simultaneously increase productivity by $20 \%$. In order to prospect scenarios with HRC systems, a computational model was used in this case study. Therefore, a workstation assessment regarding ergonomics and productivity was carried out to design and to feed the model.

\subsection{Workstation Assessment}

\subsubsection{Ergonomic Work Analysis}

Direct observation was performed on the workstation under analysis in order to characterize the environment, the process, and the main variables as well as their interconnections. The most critical WMSD risk factors were identified, such as awkward postures and repetitive tasks. Therefore, a replica-workstation for manual assembly of electronic components was built considering the same dimensions in order to replicate body ranges and postures.

The workstation layout is presented in Figure 5. and consists of reaching pieces on both the left and right sides at different heights, and to assemble them in the center (in front of the worker). Thus, the characteristic movements are vertical reach movements at shoulder level, sometimes with lateral flexion of the trunk and displacement in steps to the side. 


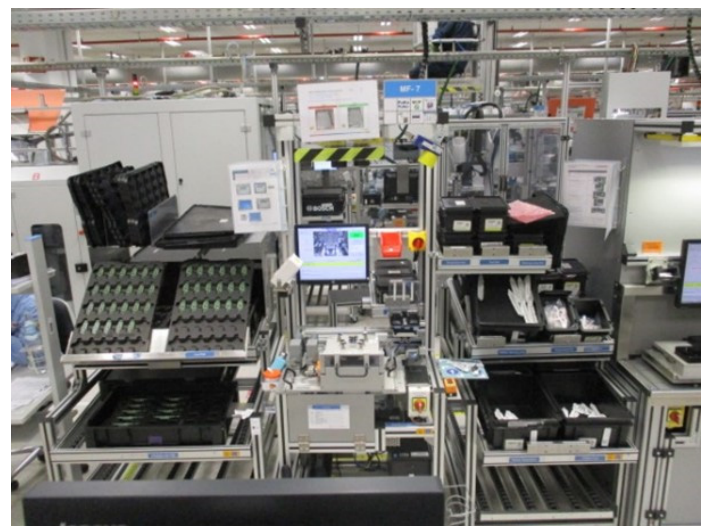

(a)

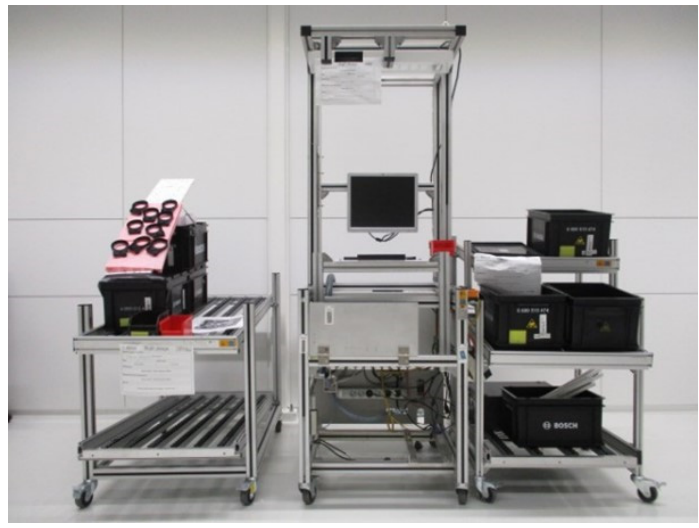

(b)

Figure 5. Workstation layout: (a) Original; (b) Replica.

The piece to be assembled consists of seven components which are presented in Figure 6. From P1 to P3, the components are on the left side, from P4 to P6, on the right side, and P7 is placed in front of the worker (close to the assembly table).

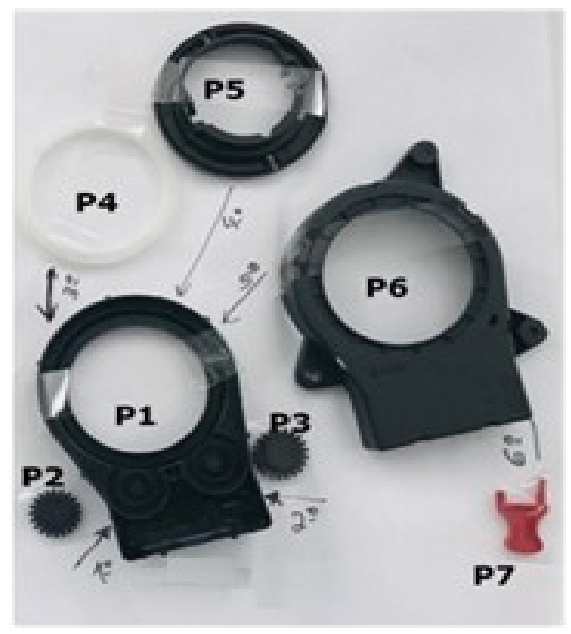

(a)

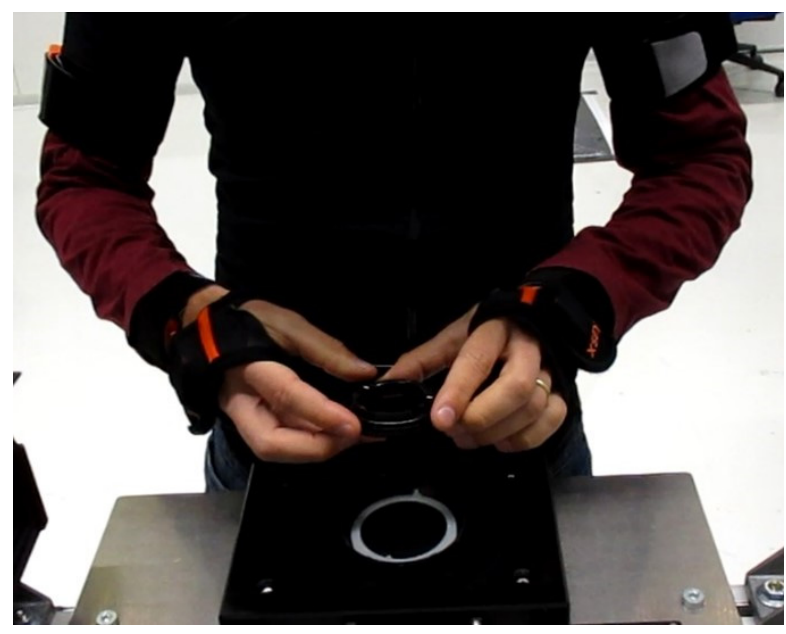

(b)

Figure 6. Assembly piece and sequence: (a) Components; (b) Manual handling.

In order to obtain data from all different dimensions of the Portuguese population, the worker's sample was divided in three classes of percentiles. In total, six workers were chosen (one female and one male from each of the percentile classes presented in Table 4). The anthropometric dimension "stature" was the dimension used as reference [60].

Table 4. Stature percentile classes for female and male.

\begin{tabular}{ccc}
\hline Percentile & Female $(\mathbf{m m})$ & Male $(\mathbf{m m})$ \\
\hline$[5-35]$ & $1456-1539$ & $1565-1660$ \\
{$[35-65]$} & $1540-1589$ & $1661-1718$ \\
{$[65-95]$} & $1590-1673$ & $1719-1814$ \\
\hline
\end{tabular}

\subsubsection{Physical Workload Assessment}

RULA was the ergonomic method chosen for physical workload assessment. Workers were equipped with wearable sensors and RULA score was obtained automatically with an algorithm developed by $\mathrm{Xsens}^{\circledR}$. The algorithm estimates the percentage of time that 
the subject was in each of the four risk levels defined by RULA during the task. The procedure involved the following steps: sociodemographic data (age, height, weight) of the six workers were collected; body dimensions were collected as input to the software; biomechanical data were collected in real time of work activity [61] at a frequency of $120 \mathrm{~Hz}$ [62]; data were transmitted wirelessly to a computer loaded with a software that allows the movements to be observed, recorded, and analyzed; the speed of the movements was defined by each participant, according to their individual abilities; workers performed the task continuously during six cycle times. Figure 7 shows the sensors placement that was followed by calibration and recording using Xsens ${ }^{\circledR}$ MVN software. Figure 8 shows workers performing the assembly tasks with the sensors capturing movements.

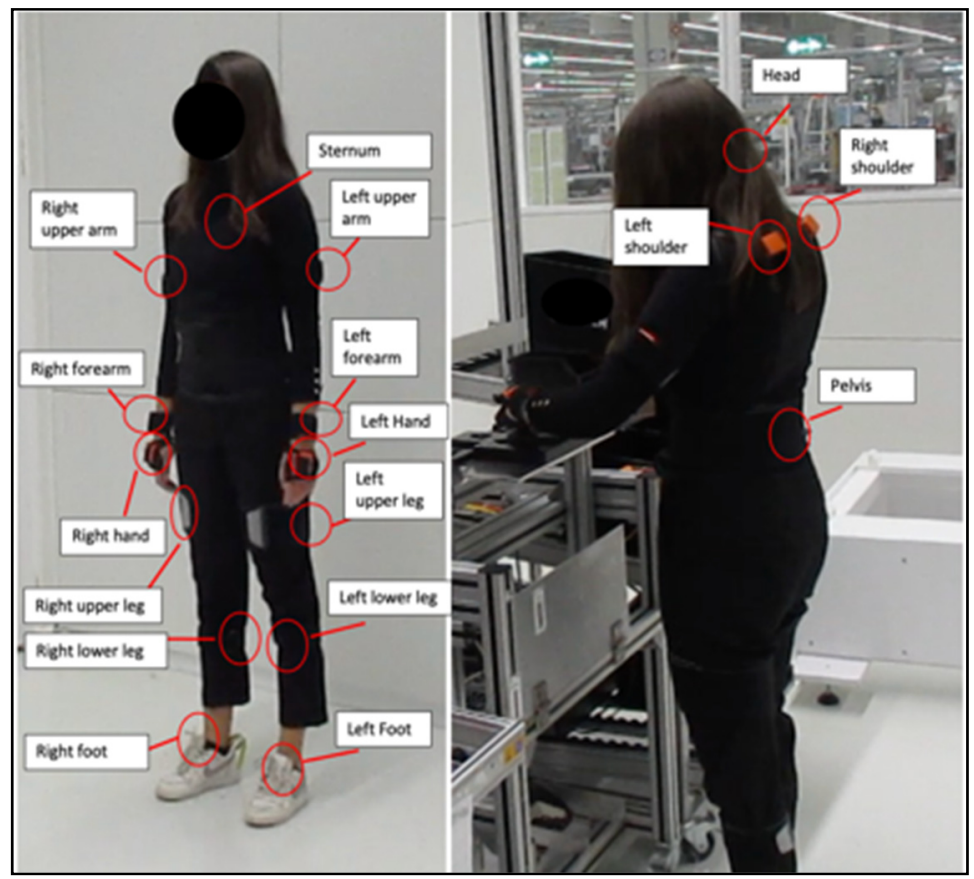

Figure 7. Sensors' placement on the body.

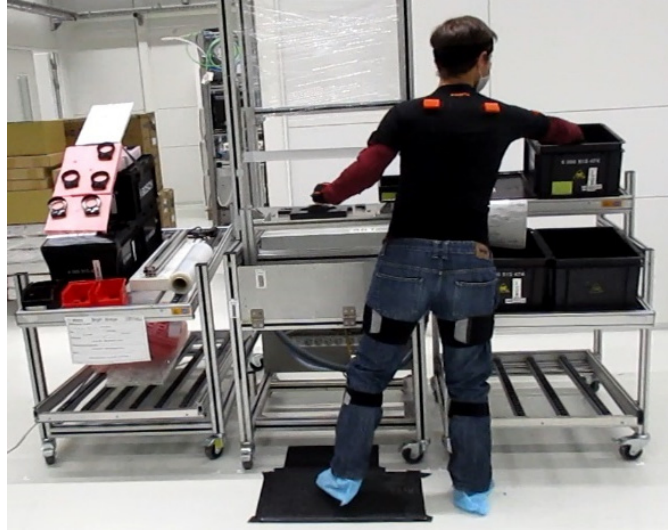

(a)

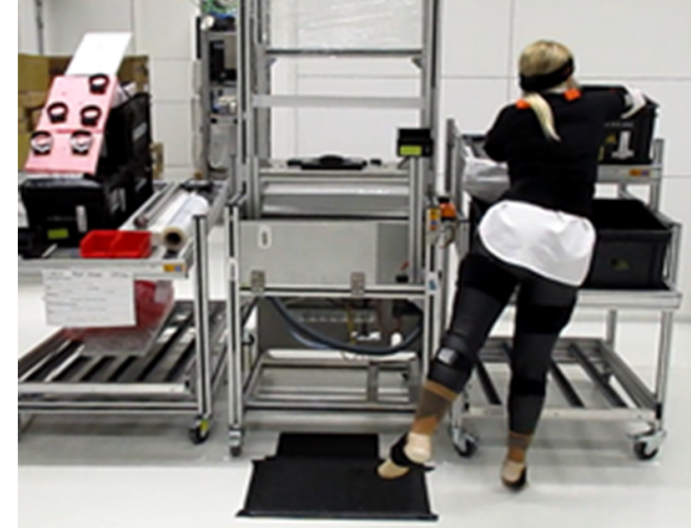

(b)

Figure 8. Assembly task with sensors for obtaining RULA scores: (a) Highest percentile; (b) Lowest percentile.

The average percentages of time exposure obtained for each risk level were the following: $0.2 \%$ acceptable, $77.5 \%$ low risk, $19.3 \%$ medium risk, and 3.0\% high risk, which was considered RULA $=4$. Therefore, according to Table 1, the model used "Physical Risk Level II" for simulation purposes. 


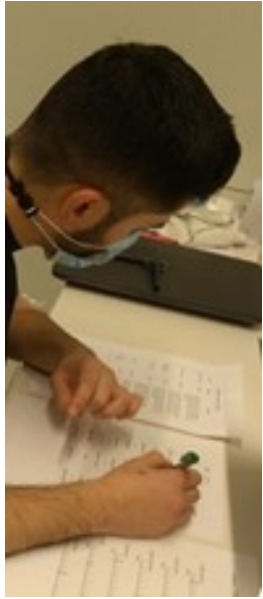

(a)

\subsubsection{Mental Workload Assessment}

The ergonomic method chosen for mental workload assessment was NASA-TLX [49]. The questionnaire was applied to the six volunteers after a work shift. The procedure was: to explain the definition of the six items (mental demand, physical demand, temporal demand, performance, effort, and frustration); to ask the workers to choose in a scale their own perception on the task; and finally, to ask each worker to choose the item they consider most relevant for each of the fifteen pairs of items presented. The average results are shown in Figure 9b. The overall workload is 44, which means "moderate", and no item is especially critical. It was classified as low mental risk level according to Table 2. Therefore, the model considers "Mental Risk Level I" for simulation purposes.

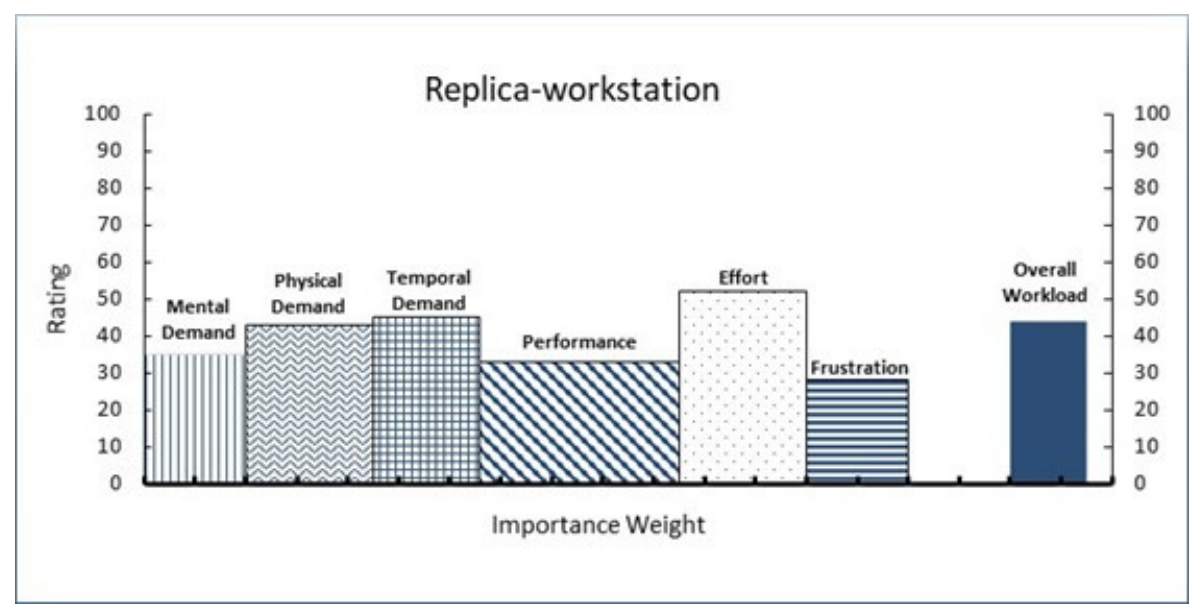

(b)

Figure 9. NASA-TLX results for the replica-workstation; (a) Questionnaire application; (b) Results.

\subsubsection{Cycle Time}

Time study is used to determine the time required by a qualified and well-trained person working at a normal pace to do a specified task [63]. A digital stopwatch was used to record $20 \mathrm{~min}$ of task executions. The average cycle time in the replica-workstation was $23.10 \mathrm{~s}$.

The results obtained in the assessment phase are summarized in Table 5. to be used in the modeling and simulation phases.

Table 5. Summary of assessed results to be modeled.

\begin{tabular}{cccc}
\hline EWA & RULA & NASA-TLX & Cycle Time \\
\hline Workstation variables & Risk Level II & Risk Level I & $23.10 \mathrm{~s}$ \\
\hline
\end{tabular}

\subsection{Modeling}

The use of system dynamics allows the systemic contextualization of factors assessed in the workstation, a mathematical description of their interrelationship, and the prospection of scenarios in non-linear relationships. A system dynamics was designed in the Vensim software [64] to model the whole environment (See Appendix A-Figure A1 and Table A1). The production system was based on the model described by Sterman [24] (e.g., "work in process", "production start rate" and "production rate"). Furthermore, the construction of the model was adapted to the characteristics of the context under study. In this sense, the "work for process" is a complement factor inserted along with its input rate and influence variables. The structure of employees' dynamics and its reflection on the production system follows an analogous context [15], in which the same phenomenon is analyzed. The model calibration was performed aiming to drive the system's behavior 
to values close to those observed and recorded for the real system. Therefore, certain equations receive an adjustment constant (e.g., equation Time to gain Knowledge). The "Time to gain Knowledge (TK)" is inversely proportional to the "Cycle Frequency (CF)" since frequent cycles (with greater repetition) result in less time to gain knowledge (faster learning through repetition), being mathematically formulated as: TK $=$ constant $/ \mathrm{CF}$. The constant value calibrated in this study was 480 , resulting in TK $=480 / C F$. The variables "Mental Overload" (MO), "Physical Overload" (PO), and "Knowledge Required" (KR) were entered as a function of the LoC (Table 6). The variable "Postural Requirement" (PR) is an intermediate variable between the $\mathrm{LoC}$ and $\mathrm{PO}$ for the model to support the insertion of values obtained from any ergonomic method chosen to assess physical effort. The integration increment was set to $1 / 5$ of the value of the shortest time constant. Since the analysis is focused on operational dynamics whose effects occur in a relatively short time, the simulation horizon was defined in a work shift ( 8 hours). The total human workload value was subjectively weighted by the modelers at $33 \%$ for mental demands (Risk Level I) and $67 \%$ for physical demands (Risk Level II), which means that physical factors were considered twice more critical in the current study. In addition, a very important aspect for this analysis is the insertion of the LoC influences in the simulation model. In this case, the insertion was done by the definition of values in ordinal scales of five levels, in which level 0 of collaboration means a workstation without robot, and level 4 means maximum collaboration. As LoC influences on mental workload, postural demand, and knowledge necessary to perform the task, the values defined by the modelers to configure the model were assessed and are shown in Table 6.

Table 6. Description of LoC with their influence on the model.

\begin{tabular}{cccccc}
\hline & & \multicolumn{4}{c}{ Level of Collaboration } \\
& $\mathbf{0}$ & $\mathbf{1}$ & $\mathbf{2}$ & $\mathbf{3}$ & $\mathbf{4}$ \\
\hline Mental & 0.5 & 1.0 & 2.0 & 3.0 & 4.0 \\
Physical & 4.0 & 3.0 & 2.0 & 1.0 & 0.5 \\
Knowledge & $100 \%$ & $90 \%$ & $70 \%$ & $50 \%$ & $30 \%$ \\
\hline
\end{tabular}

The relationship among LoC, cycle time, and sick leaves over the simulation horizon is presented in Table 7 which turns out to be very useful for the interpretation of the system. The simulation shows that the most favorable scenario to avoid the incidence of occupational diseases, which leads to employees on leave, corresponds to the highest LoC. Although this level means a greater frequency of cycles (due to the reduced cycle time) and the performance of mental workload, the reduction in postural load seems to compensate for these factors.

Table 7. Comparison of sick leave and productivity for different LoC.

\begin{tabular}{ccc}
\hline LoC & Sick Leave & Cycle Time \\
\hline $\mathbf{1}$ & $-5.6 \%$ & $0 \%$ \\
$\mathbf{2}$ & -11.8 & $3.2 \%$ \\
$\mathbf{3}$ & -26.5 & -6.9 \\
$\mathbf{4}$ & $-30.4 \%$ & $-10.1 \%$ \\
\hline
\end{tabular}

The results demonstrate that inserting an industrial HRC system is complex. Both physical and mental workload may affect leave rate and productivity, which significantly change the prospective scenarios.

\subsection{Evaluation}

\subsubsection{Technical Evaluation}

Some critical checks were performed in order to verify if an industrial HRC system was technically practicable in the workstation with the mentioned characteristics. The 
main possibilities for a cobot to be useful are delivering, handling, and assembling. In this regard, the main complexities are those related to the work pieces: geometry, dimensions, loads, and materials; and related to the organization: assembly location, layout, ranges, and sequences [65]. The critical technical issues follow the list presented in [14].

- Delivering: without perceived restrictions;

- Handling: three small components would be difficult for a cobot to manipulate;

- Assembly: some components are resistant to insertion, the assembly table is overconstrained, the assembly process demands reorientation of previous assembled components, and components must be compressed during assembly.

In summary, the small pieces must be manipulated by the worker and most of the assembly tasks require human skills to guarantee quality in the production line. Other tasks are considered feasible in terms of robot execution. For example, it is technically capable of handling and delivering the four larger pieces.

\subsubsection{Ergonomic Evaluation}

An ergonomic intervention in the workstation by implementing an industrial HRC system will definitively change organizational, physical, and cognitive domains. In the new layout, work pieces must be delivered to the worker in a location closer to him, thus avoiding inappropriate postures on his part. By decreasing RULA scores, less WMSD is expected in the production line [66]. On the other hand, mental workload also increases with repeatability of movements as psychological well-being depends on production flexibility [67].

The simulations showed the behavior of the system regarding the occurrence of sick leave and productivity for different LoC. Task subdivision increased worker's skills to accomplish the tasks and directly increased productivity. However, the influence of physical overload on output showed that productivity is also associated with stereotyped movement, which is often consequence of repeatability or excessive task subdivision. Therefore, it is not recommended to overpush. Moreover, physiological recovery is needed in order to decrease the influence of physical overload on leave rate [15].

In general, the inclusion of an industrial HRC system is beneficial for ergonomics. The main attention points are related to the new pace of work and the division of tasks between the worker and the cobot. These factors are better discussed in the economic evaluation.

\subsubsection{Safety Evaluation}

Safety requirements: Due to the risk of collisions, a robot working without fences represents a risk in the HRC system [68]. Safety management, sensors, and motion planning and control are the most important to avoid collisions [27]. According to ISO/TS 15,066 [56], the safety methods may vary for different LoC: safety-rated monitored stop, hand guiding, speed and separation monitoring, and power and force limiting.

Risk assessment: Similar assembly application with HRC evaluated as low risk for the human [9]. However, an evaluation is important due to individual scenarios of a collaboration [69]. In this work, it has been considered that this evaluation does not change as the light-weighted pieces are delivered always at the same place by the robot, and safety requirements may follow robot's capabilities in different LoC, according to Table 3.

\subsubsection{Economic Evaluation}

Considering the above mentioned regarding technical, ergonomic, and safety evaluations, an economic evaluation aims at recognizing the tasks for which a cobot provides value to the production process. As stated in [14], it is important to integrate organizational and economic factors for a better collaborative workstation.

Table 8 presents the division of the workstation tasks between human and cobot. In this case study, the assembly tasks must be performed by the worker, which means that all the value-added tasks were allocated to the worker. However, the cobot is capable of handling and delivering P1, P4, P5, and P6 (larger pieces), which means time saving in the 
production line. Moreover, according to the prospections of the model, less absenteeism is expected due to WMSD, which means maintaining human resources and knowledge.

Table 8. Division of the workstation tasks.

\begin{tabular}{|c|c|c|c|c|c|}
\hline Component & Task & Human & Cobot & Value Added & Time Saving \\
\hline \multirow{3}{*}{ P1 } & Delivering & & $x$ & & + \\
\hline & Handling & & $x$ & & + \\
\hline & Assembly & $X$ & & + & \\
\hline \multirow{3}{*}{$\mathrm{P} 2$} & Delivering & & $x$ & & + \\
\hline & Handling & $x$ & & & \\
\hline & Assembly & $X$ & & + & \\
\hline \multirow{3}{*}{ P3 } & Delivering & & $x$ & & + \\
\hline & Handling & $x$ & & & \\
\hline & Assembly & $X$ & & + & \\
\hline \multirow{3}{*}{$\mathrm{P} 4$} & Delivering & & $X$ & & + \\
\hline & Handling & & $X$ & & + \\
\hline & Assembly & $X$ & & + & \\
\hline \multirow{3}{*}{ P5 } & Delivering & & $X$ & & + \\
\hline & Handling & & $X$ & & + \\
\hline & Assembly & $X$ & & + & \\
\hline \multirow{3}{*}{ P6 } & Delivering & & $x$ & & + \\
\hline & Handling & & $x$ & & + \\
\hline & Assembly & $X$ & & + & \\
\hline \multirow{3}{*}{ P7 } & Delivering & & $x$ & & + \\
\hline & Handling & $x$ & & & \\
\hline & Assembly & $X$ & & + & \\
\hline
\end{tabular}

\subsection{Decision}

Considering the objectives, assessments, simulations, evaluations, and investments to be made, the workstation condition justifies the implementation of an industrial HRC system. It has been taken into account that by thinking on the whole system, higher levels of automation do not necessarily guarantee higher levels of productivity, safety, or operator well-being [70]. Higher LoC may induce other problems, such as confusion, complacency, or loss of certain skills. According to the classification suggested in [55], in order to achieve management expectations in short- and long-terms, a meaningful decision would be upon a cobot with capabilities in the Level 3 presented in Table 3.

Here are some final considerations. The new workstation must: ensure the cobot arm to reach the work pieces; consider workers anthropometric dimensions in the layout design; choose adequate technologies for gripping, safety, and recognition and awareness sensors.

\section{Conclusions}

Inserting a cobot into an assembly line is a complex decision. The dynamics of the elements that interact with each other can result in counter-intuitive effects. In this context, decision-making needs to be carefully thought out and developed. The current framework addresses the challenge of implementing a cobot. Ergonomics, safety, and productivity aspects were discussed based on system dynamics in a context of industrial assembly process. The system behavior and its prospective scenarios with HRC were key to managerial evaluation. Finally, a decision was made based on reliable data instead of a mental model, drastically reducing the risk of failure when deciding upon a HRC system. Therefore, this framework was presented to improve managerial decision assertiveness. Future work is intended to be developed in order to simplify the model and maintaining its usefulness. We also recommend the practical application of this framework in other assembly lines that meet the demand for the insertion of a cobot. 
Author Contributions: Conceptualization and Methodology, G.D.B.; Model, G.D.B., and R.A.N.; Data Acquisition, G.D.B., H.G., A.C. (André Cardoso), and D.L.d.M.; Writing-Original Draft Preparation, G.D.B. and A.M.R.; Writing-Review and Editing, H.G., A.C. (André Cardoso), and D.L.d.M.; Supervision, A.C. (Ana Colim), P.C., E.M., and P.A. All authors have read and agreed to the published version of the manuscript.

Funding: This work was supported by European Structural and Investment Funds in the FEDER component, through the Operational Competitiveness and Internationalization Programme (COMPETE 2020) [Project $n^{\circ}$ 39479; Funding Reference: POCI-01-0247-FEDER-39479] and by FCT-Fundacão para a Ciência e Tecnologia within the R\&D Units Project Scope: UIDB/00319/2020.

Institutional Review Board Statement: The study was conducted according to the guidelines of the Declaration of Helsinki and approved by the Ethic Committee approval number is CEICVS 137/2020.

Informed Consent Statement: Informed consent was obtained from all subjects involved in the study.

Data Availability Statement: The Appendix A is the source of data generated during the study. Researchers can replicate the results by following the Stock and Flow Map together with equations.

Conflicts of Interest: The authors declare no conflict of interest. The sponsors had no role in the design, execution, interpretation, or writing of the study.

\section{Appendix A}

Table A1. Model equations.

\begin{tabular}{|c|c|c|}
\hline Label & Equation & Unit \\
\hline Work for process (WFP) & $\mathrm{WFP}=\int_{\mathrm{t}_{0}}^{\mathrm{t}}[\mathrm{PAr}-\mathrm{PSr}] \mathrm{dt}+\mathrm{WFP}_{\mathrm{t}_{0}}$ & Tangible goods \\
\hline Work in process (WIP) & $\mathrm{WIP}=\int_{\mathrm{t}_{0}}^{\mathrm{t}}[\mathrm{PSr}-\mathrm{Pr}] \mathrm{dt}+\mathrm{WIP}_{\mathrm{t}_{0}}$ & Tangible goods \\
\hline Production rate $(\operatorname{Pr})$ & $\operatorname{Pr}=\frac{\mathrm{WIP}}{\mathrm{MCT}}$ & Tangible goods/Week \\
\hline Production start rate (PSr) & $\mathrm{PSr}=\frac{\mathrm{WFP}}{\mathrm{PCt}}$ & Tangible goods/Week \\
\hline Desired production start rate (DPSr) & $\mathrm{DPS} r=\mathrm{DPr}$ & Tangible goods/Week \\
\hline Adjustment for work for process (AjWFP) & $\mathrm{AjWIP}=\frac{(\mathrm{DWFP}-\mathrm{WFP})}{\text { WFP adjustment time }}$ & Tangible goods/Week \\
\hline Desired work for process (DWFP) & DWIP $=$ PSr $\cdot$ PCt & Tangible goods \\
\hline Desired production rate (DPr) & $\mathrm{DPr}=\frac{\text { Available production time }}{\text { Desired production }}$ & Tangible goods/Week \\
\hline Manufacturing cycle time (MCT) & $\mathrm{MCT}=\int_{\mathrm{t}_{0}}^{\mathrm{t}}(\mathrm{CTAjrdt})+\mathrm{WFP}_{\mathrm{t}_{0}}$ & Week \\
\hline Production activation rate (PAr) & PAr $=$ DPAr & Tangible goods/Week \\
\hline Production correction time (PCt) & $\mathrm{PCt}=\frac{\text { Maximum work in process }-\mathrm{WIP}}{\mathrm{DPr}}$ & Week \\
\hline Cycle time adjustment rate (CTAjrdt) & CTAjrdt $=\frac{\mathrm{MPr}}{\text { Time of percep. of meeting the goal } \cdot I P}$ & \\
\hline Desired production activation rate (DPAr) & $\mathrm{DPAr}=\mathrm{AjWFP}+\mathrm{DPSr}$ & Tangible goods/Week \\
\hline Pressure index in relation to meeting the goal (IP) & $\mathrm{IP}=\frac{\mathrm{DPr}}{\mathrm{Pr}}$ & \\
\hline Minimum cycle time $(\mathrm{MiCt})$ & $\mathrm{MiCt}=\mathrm{f}(\mathrm{KAj})$ & Week \\
\hline Knowledge adjustment (KAj) & $\mathrm{KAj}=\frac{\mathrm{KI}}{\mathrm{KR}}$ & \\
\hline Cycle frequency $(\mathrm{CF})$ & $\mathrm{CF}=\frac{1}{\mathrm{MCT}}$ & Cycles \\
\hline Postural requirement (PR) & $\mathrm{PR}=\mathrm{f}($ Level of Collaboration $)$ & \\
\hline Mental overload (MO) & $\mathrm{MO}=\mathrm{f}($ Level of Collaboration $)$ & \\
\hline Physical overload (PO) & $\mathrm{PO}=\mathrm{f}($ Level of Collaboration $)$ & \\
\hline Knowledge required (KR) & $\mathrm{KR}=\mathrm{f}($ Level of Collaboration) & Knowledge \\
\hline Effective employees (EE) & $\mathrm{EE}=\int_{\mathrm{t}_{0}}^{\mathrm{t}}[\mathrm{Rr}-\mathrm{Lr}] \mathrm{dt}+\mathrm{EE}_{\mathrm{t}_{0}}$ & Employees \\
\hline $\begin{array}{c}\text { Return rate }(\mathrm{Rr}) \\
\text { Leave rate }(\mathrm{Lr})\end{array}$ & $\mathrm{Lr}=\frac{\mathrm{Rr}=\frac{\mathrm{EL}}{\text { Retyru time }}}{\text { Time to disease incidence }}$ & $\begin{array}{l}\text { Employees/Week } \\
\text { Employees/Week }\end{array}$ \\
\hline Employees on leave (EL) & $\mathrm{EL}=\int_{\mathrm{t}_{0}}^{\mathrm{t}}[\mathrm{Lr}-\mathrm{Rr}] \mathrm{dt}+\mathrm{EL}_{\mathrm{t}_{0}}$ & Employees \\
\hline Time to gain knowledge (TK) & $\mathrm{TK}=\frac{480}{\mathrm{CF}}$ & Week \\
\hline Knowledge index (KI) & $\mathrm{KI}=\int_{\mathrm{t}_{0}}^{\mathrm{t}}[\mathrm{LEr}-\mathrm{LKr}] \mathrm{dt}+\mathrm{KI}_{\mathrm{t}_{0}}$ & \\
\hline Learning rate (LEr) & $\mathrm{LEr}=\frac{\mathrm{KR}-\mathrm{KI}}{\mathrm{TK}}$ & Knowledge/Week \\
\hline Loss of knowledge rate (LKr) & $\mathrm{LKr}=\frac{\mathrm{EE}-\text { Line employees }}{\text { Time to disease incidence }}$ & Knowledge/Week \\
\hline
\end{tabular}




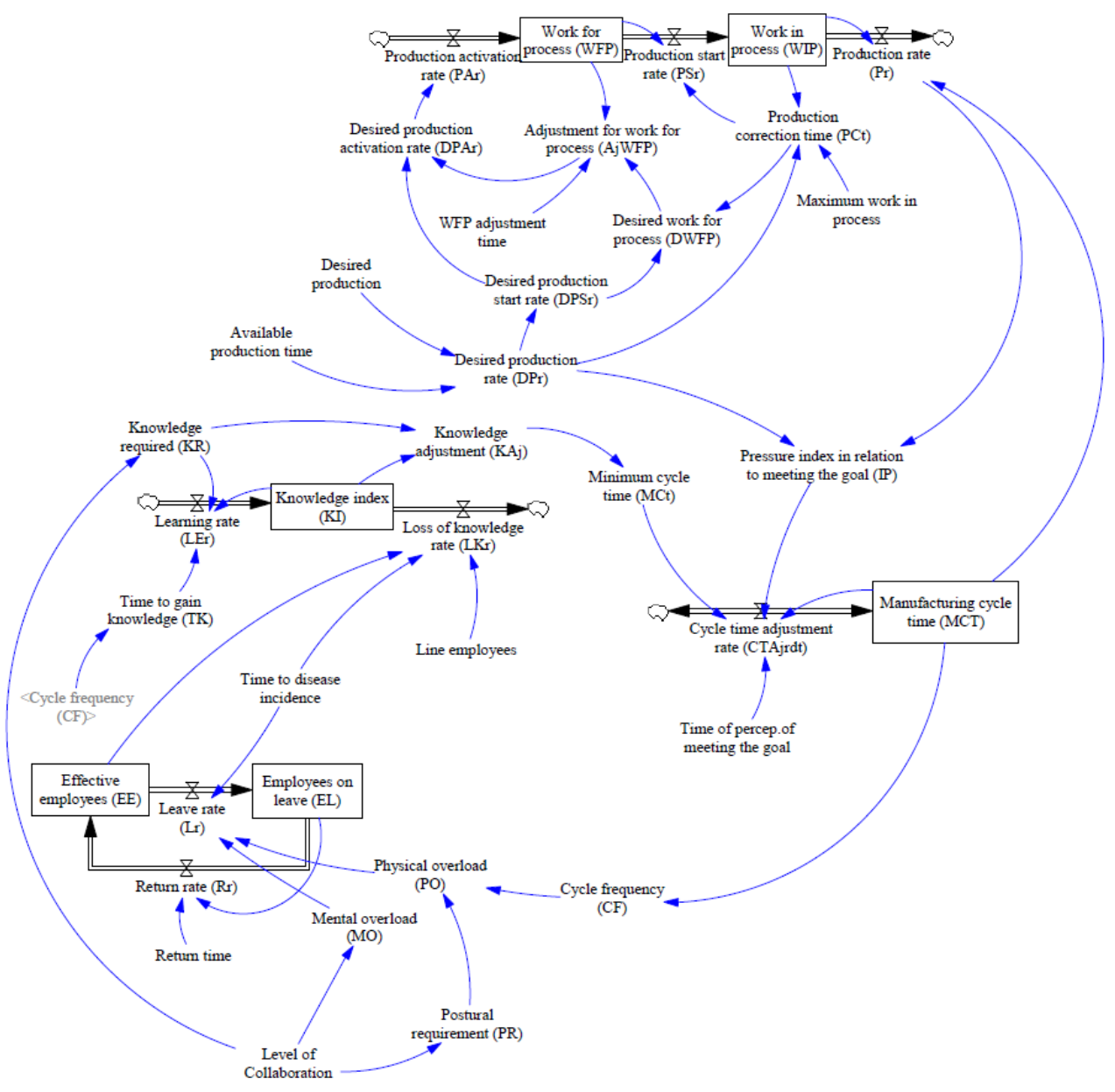

Figure A1. Stock and Flow Map.

\section{References}

1. Borges, G.D.; Neto, R.A.; de Mattos, D.L.; Merino, E.A.D.; Carneiro, P.; Arezes, P. A Computational Assessment of Ergonomics in an Industrial Human-Robot Collaboration Workplace Using System Dynamics. Int. Conf. Appl. Hum. Factors Ergon. 2021, 268, 60-68.

2. Borges, G.D.; Carneiro, P.; Arezes, P. Human Factors Effects on a Human-Robot Collaboration System: A Modelling Approach. In Congress of the International Ergonomics Association; Springer: Cham, Switzerland, 2021; Volume 223, pp. 829-838.

3. Peternel, L.; Kim, W.; Babic, J.; Ajoudani, A. Towards ergonomic control of human-robot co-manipulation and handover. In Proceedings of the 2017 IEEE-RAS 17th International Conference on Humanoid Robotics (Humanoids), Birmingham, UK, 15-17 November 2017; pp. 55-60. [CrossRef]

4. Roveda, L.; Haghshenas, S.; Caimmi, M.; Pedrocchi, N.; Tosatti, L.M. Assisting operators in heavy industrial tasks: On the design of an optimized cooperative impedance fuzzy-controller with embedded safety rules. Front. Robot. AI 2019, 6, 75. [CrossRef]

5. Robertson, J.; Jayne, C.; Oakman, J. Work-related musculoskeletal and mental health disorders: Are workplace policies and practices based on contemporary evidence? Saf. Sci. 2021, 138, 105098. [CrossRef]

6. Battini, D.; Delorme, X.; Dolgui, A.; Persona, A.; Sgarbossa, F. Ergonomics in assembly line balancing based on energy expenditure: A multi-objective model. Int. J. Prod. Res. 2016, 54, 824-845. [CrossRef]

7. Bokhorst, J.A.C.; Nomden, G.; Slomp, J. Performance evaluation of family-based dispatching in small manufacturing cells. Int. J. Prod. Res. ISSN 2008, 46, 6305-6321. [CrossRef]

8. EU-OSHA. Work-Related Musculoskeletal Disorders_Facts and Figures; European Agency for Safety and Health at Work: Bilbao, Spain, 2020. [CrossRef]

9. Gervasi, R.; Mastrogiacomo, L.; Franceschini, F. A conceptual framework to evaluate human-robot collaboration. Int. J. Adv. Manuf. Technol. 2020, 108, 841-865. [CrossRef]

10. Vicentini, F.; Pedrocchi, N.; Beschi, M.; Giussani, M.; Iannacci, N.; Magnoni, P.; Pellegrinelli, S.; Roveda, L.; Villagrossi, E.; Askarpour, M.; et al. PIROS: Cooperative, Safe and Reconfigurable Robotic Companion for CNC Pallets Load/Unload Stations. In Bringing Innovative Robotic Technologies from Research Labs to Industrial End-Users; Springer: Cham, Switzerland, 2020 ; p. 136. [CrossRef] 
11. Charalambous, G.; Fletcher, S.; Webb, P. Identifying the key organisational human factors for introducing human-robot collaboration in industry: An exploratory study. Int. J. Adv. Manuf. Technol. 2015, 81, 2143-2155. [CrossRef]

12. Badri, A.; Boudreau-trudel, B.; Souissi, A.S. Occupational health and safety in the industry 4.0 era: A cause for major concern? Saf. Sci. 2018, 109, 403-411. [CrossRef]

13. Roveda, L.; Spahiu, B.; Terkaj, W. On the proposal of a unified safety framework for industry 4.0 multi-robot scenario. CEUR Workshop Proc. 2019, 2400, 1-8.

14. Gualtieri, L.; Rojas, R.A.; Garcia, M.A.R.; Rauch, E.; Vidoni, R. Implementation of a Laboratory Case Study for Intuitive Collaboration Between Man and Machine in SME Assembly. In Industry 4.0 for SMEs; Palgrave Macmillan: Cham, Switzerland, 2020; pp. 335-382. ISBN 9783030254247.

15. de Mattos, D.L.; Neto, R.A.; Merino, E.A.D.; Forcellini, F.A. Simulating the influence of physical overload on assembly line performance: A case study in an automotive electrical component plant. Appl. Ergon. 2019, 79, 107-121. [CrossRef]

16. Salvendy, G. Handbook of Human Factors; John Wiley \& Sons: Hoboken, NJ, USA, 2012; ISBN 9780470528389.

17. Bauer, W.; Bender, M.; Braun, M.; Rally, P.; Sholtz, O. Lightweight Robots in Manual Assembly-Best to Start Simply! Fraunhofer Institute for Industrial Engineering IAO: Stuttgart, Germany, 2016.

18. Pini, F.; Leali, F.; Ansaloni, M. A systematic approach to the engineering design of a HRC workcell for bio-medical product assembly. In Proceedings of the Emerging Technologies \& Factory Automation (ETFA), Luxembourg, 8-11 September $2015 ;$ p. 8.

19. Tan, J.T.C.; Duan, F.; Zhang, Y.; Watanabe, K.; Kato, R.; Arai, T. Human-Robot Collaboration in Cellular Manufacturing: Design and Development. In Proceedings of the IEEE/RSJ International Conference on Intelligent Robots and Systems, St. Louis, MO, USA, 10-15 October 2009; pp. 29-34.

20. Stanton, N.A.; Hedge, A.; Brookhuis, K.; Salas, E.; Hendrick, H.W. Handbook of Human Factors and Ergonomics Methods; CRC Press: Boca Raton, FL, USA, 2004.

21. Salmon, P.M.; Walker, G.H.; Read, G.J.M.; Goode, N.; Stanton, N.A. Fitting methods to paradigms: Are ergonomics methods fit for systems thinking? Ergonomics 2017, 60, 194-205. [CrossRef] [PubMed]

22. Busch, B.; Toussaint, M.; Lopes, M. Planning Ergonomic Sequences of Actions in Human-Robot Interaction. In Proceedings of the IEEE International Conference on Robotics and Automation, Brisbane, QLD, Australia, 21-25 May 2018; pp. $1916-1923$.

23. Green, S.A.; Billinghurst, M.; Chen, X.; Chase, J.G. Human-Robot Collaboration: A Literature Review and Augmented Reality Approach in Design. Int. J. Adv. Robot. Syst. 2008, 5, 1-18. [CrossRef]

24. Sterman, J. Business Dynamics: Systems Thinking and Modeling for a Complex World; Education, M.-H.H., Ed.; Irwin/McGraw-Hill: Boston, MA, USA, 2004; ISBN 0072311355, 9780072311358.

25. Karsh, B.; Waterson, P.; Holden, R.J. Crossing levels in systems ergonomics: A framework to support 'mesoergonomic' inquiry. Appl. Ergon. 2014, 45, 45-54. [CrossRef] [PubMed]

26. Shire, M.I.; Jun, G.T.; Robinson, S. The application of system dynamics modelling to system safety improvement: Present use and future potential. Saf. Sci. 2018, 106, 104-120. [CrossRef]

27. Gualtieri, L.; Rauch, E.; Vidoni, R. Emerging research fields in safety and ergonomics in industrial collaborative robotics: A systematic literature review. Robot. Comput. Integr. Manuf. 2021, 67, 101998. [CrossRef]

28. Ender, J.; Wagner, J.C.; Kunert, G.; Larek, R.; Pawletta, T.; Guo, F.B. Design of an assisting workplace cell for human-robot collaboration. In Proceedings of the International Interdisciplinary PhD Workshop, IIPhDW 2019; Institute of Electrical and Electronics Engineers Inc.: Wismar, Germany, 2019; pp. 51-56.

29. McDonald, M.; daCosta Di Bonaventura, M.; Ullman, S. Musculoskeletal Pain in the Workforce: The Effects of Back, Arthritis, and Fibromyalgia Pain on Quality of Life and Work Productivity. J. Occup. Environ. Med. 2011, 53, 765-770. [CrossRef] [PubMed]

30. Colim, A.; Faria, C.; Braga, A.C.; Sousa, N.; Carneiro, P.; Costa, N.; Arezes, P. Towards an Ergonomic Assessment Framework for Industrial Assembly Workstations-A Case Study. Appl. Sci. 2020, 10, 3048. [CrossRef]

31. Sadrfaridpour, B.; Saeidi, H.; Wang, Y. An Integrated Framework for Human-Robot Collaborative Assembly in Hybrid Manufacturing Cells. In Proceedings of the IEEE International Conference on Automation Science and Engineering (CASE), Fort Worth, TX, USA, 21-25 August 2016; pp. 462-467.

32. Sammarco, M.; Fruggiero, F.; Neumann, W.P.; Lambiase, A. Agent-based modelling of movement rules in DRC systems for volume flexibility: Human factors and technical performance. Int. J. Prod. Res. 2014, 52, 633-650. [CrossRef]

33. Pearce, M.; Mutlu, B.; Shah, J.; Radwin, R. Optimizing Makespan and Ergonomics in Integrating Collaborative Robots into Manufacturing Processes. IEEE Trans. Autom. Sci. Eng. 2018, 15, 1772-1784. [CrossRef]

34. Farid, M.; Neumann, W.P. Modelling the effects of employee injury risks on injury, productivity and production quality using system dynamics. Int. J. Prod. Res. 2020, 58, 6115-6129. [CrossRef]

35. Guérin, F.; Laville, A.; Daniellou, F.; Duraffourg, J.; Kerguelen, A. Understanding and Transforming Work: The Practice of Ergonomics; Anact: Lyon, France, 2007.

36. Ketola, R.; Toivonen, R.; Viikari-Juntura, E. Interobserver repeatability and validity of an observation method to assess physical loads imposed on the upper extremities. Ergonomics 2001, 44, 119-131. [CrossRef] [PubMed]

37. Alhonen, M.; Launis, M.; Kuorinka, T. Ergonomic Workplace Analysis; Ergonomics Section, Finnish Institute of Occupational Health: Helsinki, Finland, 1989.

38. Siong, V.Y.; Azlis-sani, J.; Hisyamudin, N.; Nor, M.; Nur, M. Ergonomic Assessment in Small and Medium Enterprises (SMEs). J. Phys. Conf. Ser. 2018, 1049, 1, 012065. [CrossRef] 
39. Middlesworth, M. A Step-by-Step Guide Rapid Upper Limb Assessment (RULA). Ergon. Plus 2019, 1, 1-13.

40. Schaub, K.; Caragnano, G.; Britzke, B.; Bruder, R. The European Assembly Worksheet. Theor. Issues Ergon. Sci. 2013, 14, 616-639. [CrossRef]

41. Waters, T.R.; Putz-Anderson, V.; Garg, A. Applications Manual for the Revised NIOSH Lifting Equation; U.S. Department of Health and Human Services: Columbus, OH, USA, 1994.

42. BAuA. Key Indicator Method for Assessing and Designing Physical Workloads During Manual Handling Operations; Federal Institute for Occupational Safety and Health: Berlin, Germany, 2019.

43. Colombini, D.; Occhipinti, E.; Álvarez-Casado, E. The Revised OCRA Checklist Method; Editorial Factors Humans: Barcelona, Spain, 2017; p. 60.

44. Kuorinka, I.; Jonsson, B.; Kilbom, A.; Vinterberg, H.; Biering-Sorensen, F.; Andersson, G.; Jorgensen, K. Standardised Nordic questionnaires for the analysis of musculoskeletal symptoms. Appl. Ergon. 1987, 18, 233-237. [CrossRef]

45. Cifrek, M.; Medved, V.; Tonkovic, S.; Ostojic, S. Clinical Biomechanics Surface EMG based muscle fatigue evaluation in biomechanics. Clin. Biomech. 2009, 24, 327-340. [CrossRef]

46. Battevi, N.; Pandolfi, M.; Cortinovis, I. Variable Lifting Index for Manual-Lifting Risk Assessment: A Preliminary Validation Study. Hum. Factors 2016, 58, 712-725. [CrossRef]

47. Fruggiero, F.; Fera, M.; Iannone, R.; Lambiase, A. Revealing a frame to incorporate safe human behaviour in assembly processes. IFAC-Pap. 2018, 51, 661-668. [CrossRef]

48. Sgarbossa, F.; Grosse, E.H.; Neumann, W.P.; Battini, D.; Glock, C.H. Human factors in production and logistics systems of the future. Annu. Rev. Control 2020, 49, 295-305. [CrossRef]

49. Hart, S.G.; Staveland, L.E. Development of NASA-TLX (Task Load Index): Results of Empirical and Theoretical Research. Adv. Psychol. 1988, 52, 139-183.

50. Reid, G.B.; Nygren, T.E. Human Mental Workload. Adv. Psychol. 1988, 52, 185-218.

51. Choi, B.; Jebelli, H.; Lee, S. Feasibility analysis of electrodermal activity (EDA) acquired from wearable sensors to assess construction workers' perceived risk. Saf. Sci. 2019, 115, 110-120. [CrossRef]

52. Pini, F.; Ansaloni, M.; Leali, F. Evaluation of operator relief for an effective design of HRC workcells. In Proceedings of the 21st IEEE International Conference on Emerging Technologies and Factory Automation, Berlin, Germany, 6-9 September 2016; pp. 1-6.

53. El Makrini, I.; Merckaert, K.; De Winter, J.; Lefeber, D.; Vanderborght, B.; Makrini, I.E.; Merckaert, K.; De Winter, J.; Lefeber, D.; Vanderborght, B.; et al. Task allocation for improved ergonomics in Human-Robot Collaborative Assembly. Interact. Stud. 2019, 20, 102-133. [CrossRef]

54. Colim, A.; Morgado, R.; Carneiro, P.; Costa, N.; Faria, C.; Sousa, N.; Rocha, L.A.; Arezes, P. Lean manufacturing and ergonomics integration: Defining productivity and wellbeing indicators in a human-robot workstation. Sustainability 2021, 13, 1931. [CrossRef]

55. Cohen, Y.; Shoval, S.; Faccio, M.; Minto, R. Deploying cobots in collaborative systems: Major considerations and productivity analysis. Int. J. Prod. Res. 2021, 1-17. [CrossRef]

56. ISO. ISO/TS 15066: 2016, Robots and Robotic Devices-Collaborative Robots; International Organization for Standardization: Geneva, Switzerland, 2016.

57. Rücker, D.; Hornfeck, R.; Paetzold, K. Investigating ergonomics in the context of human-robot collaboration as a sociotechnical system. Int. Conf. Appl. Hum. Factors Ergon. 2019, 784, 127-135.

58. di Nardo, M.; Gallo, M.; Madonna, M.; Santillo, L.C. A conceptual model of human behaviour in socio-technical systems. In International Conference on Intelligent Software Methodologies, Tools, and Techniques; Springer: Cham, Switzerland, 2015; Volume 532, pp. 598-609.

59. Kim, W.; Lorenzini, M.; Balatti, P.; Nguyen, P.D.H.; Pattacini, U.; Tikhanoff, V.; Peternel, L.; Fantacci, C.; Natale, L.; Metta, G.; et al. Adaptable workstations for human-robot collaboration: A Reconfigurable and Adaptive Human-Robot Collaboration Framework for Improving Worker Ergonomics and Productivity. IEEE Robot. Autom. Mag. 2019, 26, 14-26. [CrossRef]

60. Barroso, M.P.; Arezes, P.M.; da Costa, L.G.; Miguel, A.S. Anthropometric study of Portuguese workers. Int. J. Ind. Ergon. 2005, 35, 401-410. [CrossRef]

61. Merino, G.; Mattos, D.; Guimarães, B.; Merino, E. Ergonomic evaluation of the musculoskeletal risks in a banana harvesting activity through qualitative and quantitative measures, with emphasis on motion capture (Xsens) and EMG. Int. J. Ind. Ergon. 2019, 69, 80-89. [CrossRef]

62. Silva, L.; Rosa, C.S.; Paulo, I.I.; Mattos, N.; Giracca, C.; Merino, G.; Merino, E. Ergonomic Assessment of Musculoskeletal Risks in Postal Workers Through Motion Capture, a Case Study. In SHO2020; Portuguese Society of Occupational Safety and Hygiene: Guimarães, Portugal, 2020; pp. 85-88.

63. Barnes, R.M. Motion and Time Study Design and Measurement of Works; Wiley: New York, NY, USA, 1980.

64. Systems, V. Vensim Simulation Software; Ventana Systems, Inc.: Harvard, MA, USA, 2015; Available online: https://www.vensim. com (accessed on 26 October 2021).

65. Boothroyd, G. Assembly Automation and Product Design; CRC Press: Boca Raton, FL, USA, 2005.

66. Sharan, D.; Ajeesh, P.S. Correlation of ergonomic risk factors with RULA in IT professionals from India. WORK 2012, 41, 512-515. [CrossRef]

67. Shen, Y.; Reinhart, G. A Design Approach for Incorporating Task Coordination for Human-Robot-Coexistence within Assembly Systems. In Proceedings of the Annual IEEE Systems Conference, IEEE, Vancouver, BC, Canada, 13-16 April 2015 ; pp. 426-431. 
68. De Santis, A.; Siciliano, B.; De Luca, A.; Bicchi, A. An atlas of physical human-robot interaction. Mech. Mach. Theory 2008, 43, 253-270. [CrossRef]

69. Michalos, G.; Kousi, N.; Karagiannis, P.; Gkournelos, C.; Dimoulas, K.; Koukas, S.; Mparis, K.; Papavasileiou, A.; Makris, S. Seamless human robot collaborative assembly-An automotive case study. Mechatronics 2018, 55, 194-211. [CrossRef]

70. Lagu, A.V.; Landry, S.J. Roadmap for the Next Generation of Dynamic Function Allocation Theories and Strategies. Hum. Factors Ergon. Manuf. Serv. Ind. 2011, 21, 14-28. [CrossRef] 